\title{
A hybrid CP/MP approach to supply chain modelling, optimization and analysis
}

\author{
Paweł Sitek \\ Kielce University of Technology Al. 1000-lecia PP 7, 25-314 Kielce, \\ Poland Institute of Management Control Systems \\ e-mail:sitek@tu.kielce.pl
}

\begin{abstract}
The paper presents a concept and implementation of a novel hybrid approach to the modelling, optimization and analysis of the supply chain problems. Two environments, mathematical programming (MP) and constraint programming (CP), in which constraints are treated in different ways and different methods are implemented, were combined to use the strengths of both.

This integration and hybridization, complemented with an adequate transformation of the problem, facilitates a significant reduction of the combinatorial problem. The whole process takes place at the implementation layer, which makes it possible to use the structure of the problem being solved, implementation environments and the very data. The superiority of the proposed approach over the classical scheme is proved by considerably shorter search time and exampleillustrated wide-ranging possibility of expanding the decision and/or optimization models through the introduction of new logical constraints, frequently encountered in practice. The proposed approach is particularly important for the decision models with an objective function and many discrete decision variables added up in multiple constraints.
\end{abstract}

The presented approach will be compared with classical mathematical programming on the same data sets.

\section{INTRODUCTION}

$\mathrm{T}$ he supply chain is commonly seen as a collection of various types of companies (raw materials, production, trade, logistics, transport, etc.) working together to improve the flow of products, information and finance. As the words in the term indicate, the supply chain is a combination of its individual links in the process of supplying products (material/products and services) to the market.

Huang [1] studied the shared information of supply chain production. This consists in the information shared between each network node determined by the model, which enables production, distribution and transport planning dependent on the purpose. The shared information process is vital for effective supply chain production, distribution and transport planning. In terms of centralized planning, the information flows from each node of the network where the decisions are made. Shared information includes the following groups of parameters: resources, inventory, production, transport, demand, etc. Minimization of total costs is the main purpose of the models presented in the literature, while maximization of revenues or sales is considered to a smaller scale [12].
The vast majority of the works reviewed [2]-[7], [9],[10],[12] have formulated their models as linear programming (LP), integer programming (IP) and mixed integer linear programming (MILP) problems and solved them using the Operations Research methods. Nonlinear programming, multi-objective programming, fuzzy programming with stochastic programming are used much less frequently [12] [25].

Problems related to the design, integration and management of the supply chain affect many aspects of production, distribution, warehouse management, supply chain structure, transport modes etc. Those problems are usually closely related to each other, some may influence one another to a greater or lesser extent. Because of the interconnectedness and a very large number of different constraints: resource, time, technological, and financial, the constraint-based environments are suitable for producing "natural" solutions for highly combinatorial problems. In the literature, references to modeling and optimizing supply chain problems using constraint-based environments are relatively few in number [11], [12].

This paper deals with a problem of supply chain modelling, optimization and analysis. An important contribution of the presented hybrid CP/MP approach is to propose a hybrid implementation platform that supports the modelling, optimization and analysis of decision problems in the supply chain. In this platform two environments, mathematical programming (MP) and constraint programming $(\mathrm{CP})$, in which constraints are treated in different ways and different methods are implemented, were combined to use the strengths of both in the presented platform.

The rest of the paper is organized as follows: Section II describes our motivation and analyses the state of the art in this domain. Section III gives the concept of the novel hybrid CP/MP approach and implementation platform. The optimization model as an illustrative example is described in Section IV. Computational examples and tests of the implemented model are presented in Section V. The discussion on possible extensions of the proposed approach and conclusions is included in Section VI. 


\section{MOTIVATION}

We strongly believe that the constraint-based environment [13], [14], [16], [19] offers a very good framework for representing the knowledge and information needed for the decision support. The central issue for a constraint-based environment is a constraint satisfaction problem (CSP) [13]. Constraint satisfaction problem is the mathematical problem defined as a set of elements whose state must satisfy a number of constraints. Constraint satisfaction problems (CSPs) on finite domains are typically solved using a form of search. The most widely used techniques include variants of backtracking, constraint propagation, and local search. Constraint propagation embeds any reasoning that consists in explicitly forbidding values or combinations of values for some variables of a problem because a given subset of its constraints cannot be satisfied otherwise [16]. CSPs are frequently used in constraint programming. Constraint programming is the use of constraints as a programming language to encode and solve problems. Constraint logic programming (CLP) is a form of constraint programming (CP), in which logic programming is extended to include concepts from constraint satisfaction. A constraint logic program is a logic program that contains constraints in the body of clauses. Constraints can also be present in the goal. These environments are declarative. The declarative approach and the use of logic programming provide incomparably greater possibilities for decision problems modelling than the pervasive approach based on mathematical programming. Unfortunately, discrete optimization is not a strong suit of these environments.

Based on [8], [15], [16] and previous work [14], [17], [18], we observed some advantages and disadvantages of these environments. An integrated approach of constraint programming (CP) and mathematical programming (MP) can help to solve optimization problems that are intractable with either of the two methods alone [20]-[23]. Although mathematical programming and constraint programming have different roots, the links between the two environments have grown stronger in recent years.

Both MP and finite domain CP/CLP involve variables and constraints. However, the types of the variables and constraints that are used, and the way the constraints are solved, are different in the two approaches [23].

In both MILP and CP/CLP, there is a group of constraints that can be solved with ease and a group of constraints that are difficult to solve. The easily solved constraints in MILP are linear equations and inequalities over rational numbers.

Integrity constraints are difficult to solve using mathematical programming methods and often the real problems of MILP make them NP-hard.

In CP/CLP, domain constraints with integers are easy to solve. The system of such constraints can be solved over integer variables in polynomial time. The inequalities between more than two variables, general linear constraints and symbolic constraints are difficult to solve, which makes real problems in CP/CLP NP-hard. This type of constraints reduces the strength of constraint propagation. As a result, CP/CLP is incapable of finding even the first feasible solution. This is the greatest weakness of this approach.

As mentioned earlier, the vast majority of decisionmaking models for the problems of production, logistics, supply chain are formulated in the form of mathematical programming (MIP, MILP, IP).

Due to the structure of these models (adding together discrete decision variables in the constraints and the objective function) and a large number of discrete decision variables (integer and binary), they can only be applied to small problems. Another weakness is that only linear constraints can be used. In practice, the issues related to the production, distribution and supply chain constraints are often logical, nonlinear, etc. For these reasons the problem was formulated in a new way

The motivation and contribution behind this work was to create a hybrid method for supply chain decision problems modelling and optimization instead of using mathematical programming or constraint programming separately. It follows from the above that what is difficult to solve in one environment can be easy to solve in the other. Furthermore, such a hybrid CP/MP approach allows the use of all layers of the problem to solve it (Fig. 1). And finally, the transformation of the problem to a form that can fully exploit the strengths of the constraint propagation.

The hybrid method is not inferior to its component elements applied separately. This is due to the fact that the number of decision variables and the search area are reduced. The extent of the reduction directly affects the effectiveness of the method.

\section{III.THE CONCEPT OF THE CP/MP HYBRID APPROACH}

Due to the structure of the decision models for supply chain problems (summing of discrete decision variables in the constraints and the objective function) and a large number of discrete decision variables (integer and/or binary) they can only be applied to small problems. Another disadvantage is that only linear constraints can be used. In practice, the issues related to the production, distribution and su25]5ply chain constraints are often logical, nonlinear, etc. For these reasons the problem was formulated in a new way.

In our approach to modeling and optimization these problems we proposed the implementation platform, where:

- knowledge related to the supply chain can be expressed as linear and logical constraints (implementing all types of constraints of the previous MILP models [17], and introducing new types of constraints (logical, nonlinear, symbolic etc.));

- the decision models solved using the proposed platform can be formulated as a pure model of MILP or of CP/CLP, or it can also be a hybrid model with logical and other types of constraints;

- the problem is modelled in CP/CLP, which is far more flexible than MILP; 
- the possibility to transform the problem of using the flexibility of declarative environment (CP/CLP) is introduced;

- the novel method of constraint propagation is proposed (obtained by transforming the decision model to explore its structure and properties);

- constrained domains of decision variables, new constraints and values for some variables are transferred from $\mathrm{CP}$ based environment into MP-based environment;

- the efficiency of finding solutions to larger size problems is increased.

The concept of the proposed implementation platform is presented in Fig. 1. In the first stage, a formal model is implemented in the form of predicates in CLP and the data in the form of facts. In the next step constraint propagation is performed. Constraint propagation is one of the basic methods of CLP. As a result, the variable domains are narrowed, and in some cases, the values of variables are set, or even the solution can be found. In order to increase the efficiency of the constraint propagation transformation of the problem and its representation can be made. The transformation uses the structure and properties of the problem. The most common effect is a change in the representation of the problem by reducing the number of decision variables, and the introduction of additional constraints and variables, changing the nature of the variables, etc.

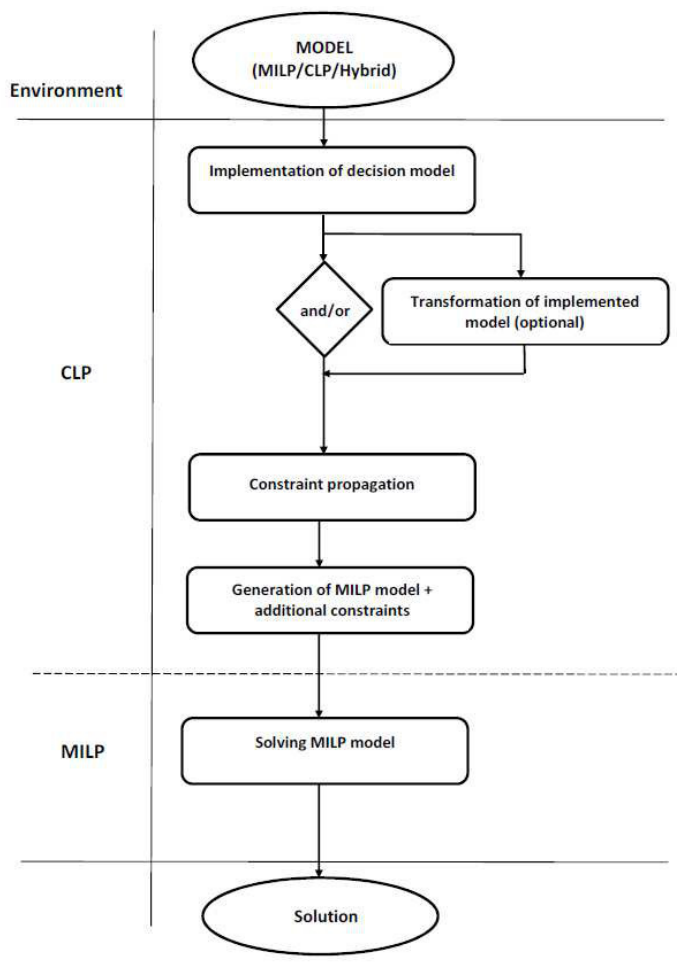

Fig. 1 Concept scheme of the CP/MP hybrid approach

The next step is the generation of the MILP model using predicates in CLP. All the information obtained in previous stages are used during the generation of the model. The final step is to solve the model by the solver MILP.
The implementation details of the CP/MP hybrid approach have been discussed in [24]. The motivation was to offer the most effective tools for model-specific constraints and solution efficiency.

\section{EXAMPLES OF SUPPLY CHAIN OPTIMIZATION}

The proposed approach was used and tested on two supply chain optimization models.

First model was formulated as a mixed linear integer programming (MILP) problem [18] under constraints (2) .. (23) in order to test the proposed approach (Fig. 1) against the classical integer programming approach [17]. Then the hybrid model (1) .. (26) was implemented and solved. Indices, parameters and decision variables used in the models together with their descriptions are summarized in Table I. The simplified structure of the supply chain network for this model, composed of producers, distributors and customers is presented in Fig. 2.

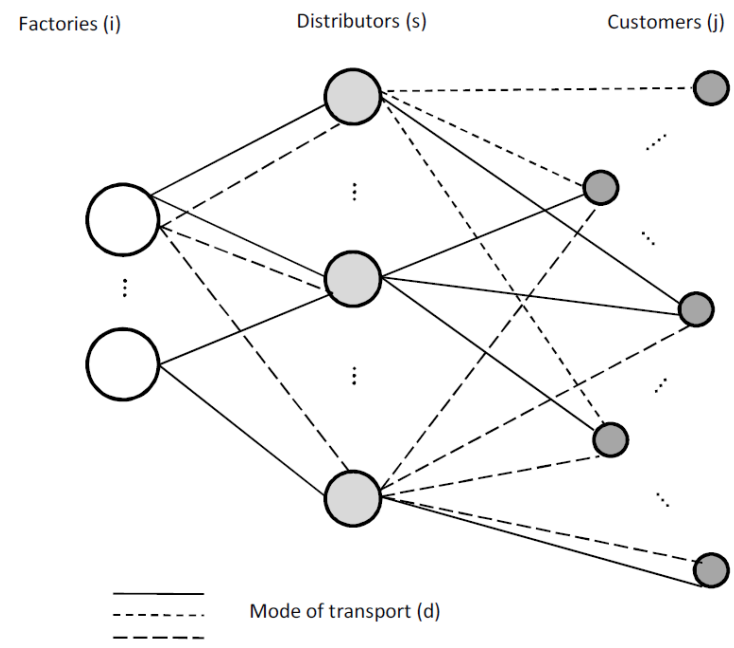

Fig. 2 The simplified structure of the supply chain network

Both models are the cost models that take into account three other types of parameters, i.e., the spatial parameters (area/volume occupied by the product, distributor capacity and capacity of transport unit), time (duration of delivery and service by distributor, etc.) and the transport mode.

The main assumptions made in the construction of these models were as follows:

- the shared information process in the supply chain consists of resources (capacity, versatility, costs), inventory (capacity, versatility, costs, time), production (capacity, versatility, costs), product (volume), transport (cost, mode, time), demand, etc;

- part of the supply chain has a structure as in Fig. 2.;

- transport is multimodal (several modes of transport, a limited number of means of transport for each mode);

- the environmental aspects of use of transport modes are taken into account;

- different products are combined in one batch of transport;

- the cost of supplies is presented in the form of a function (in this approach, linear function of fixed and variable costs); 
- the models have linear or linear and logical constraints.

TABLE I.

INDICES, PARAMETERS AND DECISION VARIABLES

\begin{tabular}{|c|c|}
\hline Symbol & Description \\
\hline \multicolumn{2}{|r|}{ Indices } \\
\hline $\mathrm{k}$ & product type $(\mathrm{k}=1 . . \mathrm{O})$ \\
\hline $\mathrm{j}$ & delivery point/customer/city $(\mathrm{j}=1 . . \mathrm{M})$ \\
\hline $\mathrm{i}$ & manufacturer/factory $(\mathrm{i}=1 . . \mathrm{N})$ \\
\hline $\mathrm{s}$ & distributor /distribution center $(\mathrm{s}=1 . . \mathrm{E})$ \\
\hline $\mathrm{d}$ & mode of transport $(\mathrm{d}=1 . . \mathrm{L})$ \\
\hline $\mathrm{N}$ & number of manufacturers/factories \\
\hline $\mathrm{M}$ & number of delivery points/customers \\
\hline $\mathrm{E}$ & number of distributors \\
\hline $\mathrm{O}$ & number of product types \\
\hline $\mathrm{L}$ & number of mode of transport \\
\hline \multicolumn{2}{|r|}{ Input parameters } \\
\hline $\mathrm{F}_{\mathrm{s}}$ & the fixed cost of distributor/distribution center $s$ \\
\hline $\mathrm{P}_{\mathrm{k}}$ & the area/volume occupied by product $k$ \\
\hline $\mathrm{V}_{\mathrm{s}}$ & distributor $s$ maximum capacity/volume \\
\hline $\mathrm{W}_{\mathrm{i}, \mathrm{k}}$ & production capacity at factory $i$ for product $k$ \\
\hline $\mathrm{C}_{\mathrm{i}, \mathrm{k}}$ & the cost of product $k$ at factory $i$ \\
\hline $\mathrm{R}_{\mathrm{s}, \mathrm{k}}$ & $\begin{array}{l}\text { if distributor } s \text { can deliver product } k \text { then } \mathrm{R}_{\mathrm{s}, \mathrm{k}}=1 \text {, otherwise } \\
\mathrm{R}_{\mathrm{s}, \mathrm{k}}=0\end{array}$ \\
\hline $\mathrm{Tp}_{\mathrm{s}, \mathrm{k}}$ & $\begin{array}{l}\text { the time needed for distributor } s \text { to prepare the shipment of } \\
\text { product } k\end{array}$ \\
\hline $\mathrm{Tc}_{\mathrm{j}, \mathrm{k}}$ & $\begin{array}{l}\text { the cut-off time of delivery to the delivery point/customer } j \text { of } \\
\text { product } k\end{array}$ \\
\hline $\mathrm{Z}_{\mathrm{j}, \mathrm{k}}$ & customer demand/order $j$ for product $k$ \\
\hline $\mathrm{Zt}_{\mathrm{d}}$ & the number of transport units using mode of transport $d$ \\
\hline $\mathrm{Pt}_{\mathrm{d}}$ & the capacity of transport unit using mode of transport $d$ \\
\hline $\mathrm{Tf}_{\mathrm{i}, \mathrm{s}, \mathrm{d}}$ & $\begin{array}{l}\text { the time of delivery from manufacturer } i \text { to distributor } s \text { using } \\
\text { mode of transport } d\end{array}$ \\
\hline $\mathrm{K} 1_{\mathrm{i}, \mathrm{s}, \mathrm{k}, \mathrm{d}}$ & $\begin{array}{l}\text { the variable cost of delivery of product } k \text { from manufacturer } i \\
\text { to distributor } s \text { using mode of transport } d\end{array}$ \\
\hline $\mathrm{R} 1_{\mathrm{i}, \mathrm{s}, \mathrm{d}}$ & $\begin{array}{l}\text { if manufacturer } i \text { can deliver to distributor } s \text { using mode of } \\
\text { transport } d \text { then } \mathrm{R} 1_{\mathrm{i}, \mathrm{s}, \mathrm{d}}=1 \text {, otherwise } \mathrm{R} 1_{\mathrm{i}, \mathrm{s} \mathrm{d}}=0\end{array}$ \\
\hline $\mathrm{A}_{\mathrm{i}, \mathrm{s}, \mathrm{d}}$ & $\begin{array}{l}\text { the fixed cost of delivery from manufacturer } i \text { to distributor } s \\
\text { using mode of transport } d\end{array}$ \\
\hline $\mathrm{Koa}_{\mathrm{s}, \mathrm{j}, \mathrm{d}}$ & $\begin{array}{l}\text { the total cost of delivery from distributor } s \text { to customer } j \\
\text { using mode of transport } d\end{array}$ \\
\hline $\mathrm{Tm}_{\mathrm{s}, \mathrm{j}, \mathrm{d}}$ & $\begin{array}{l}\text { the time of delivery from distributor } s \text { to customer } j \text { using } \\
\text { mode of transport } d\end{array}$ \\
\hline $\mathrm{K} 2_{\mathrm{s}, \mathrm{j}, \mathrm{k}, \mathrm{d}}$ & $\begin{array}{l}\text { the variable cost of delivery of product } k \text { from distributor } s \text { to } \\
\text { customer } j \text { using mode of transport } d\end{array}$ \\
\hline $\mathrm{R} 2_{\mathrm{s}, \mathrm{j}, \mathrm{d}}$ & $\begin{array}{l}\text { if distributor } s \text { can deliver to customer } j \text { using mode of } \\
\text { transport } d \text { then } \mathrm{R} 2_{\mathrm{s}, \mathrm{j}, \mathrm{d}}=1 \text {, otherwise } \mathrm{R} 2_{\mathrm{s}, \mathrm{j}, \mathrm{d}}=0\end{array}$ \\
\hline $\mathrm{G}_{\mathrm{s}, \mathrm{j}, \mathrm{d}}$ & $\begin{array}{l}\text { the fixed cost of delivery from distributor } s \text { to customer } j \\
\text { using mode of transport } d\end{array}$ \\
\hline $\operatorname{Kog}_{\mathrm{s}, \mathrm{j}, \mathrm{d}}$ & $\begin{array}{l}\text { the total cost of delivery from distributor } s \text { to customer } j \\
\text { using mode of transport } d\end{array}$ \\
\hline $\mathrm{Od}_{\mathrm{d}}$ & the environmental cost of using mode of transport $d$ \\
\hline \multicolumn{2}{|r|}{ Decision variables } \\
\hline $\mathrm{X}_{\mathrm{i}, \mathrm{s}, \mathrm{k}, \mathrm{d}}$ & $\begin{array}{l}\text { delivery quantity of product } k \text { from manufacturer } i \text { to } \\
\text { distributor } s \text { using mode of transport } d\end{array}$ \\
\hline$X a_{i, s, d}$ & $\begin{array}{l}\text { if delivery is from manufacturer } i \text { to distributor } s \text { using mode } \\
\text { of transport } d \text { then } \mathrm{Xa}_{\mathrm{i}, \mathrm{s}, \mathrm{d}}=1 \text {, otherwise } \mathrm{Xa}_{\mathrm{i}, \mathrm{s}, \mathrm{d}}=0\end{array}$ \\
\hline $\mathrm{Xb}_{\mathrm{i}, \mathrm{s}, \mathrm{d}}$ & $\begin{array}{l}\text { the number of courses from manufacturer } i \text { to distributor } s \\
\text { using mode of transport } d\end{array}$ \\
\hline $\mathrm{Y}_{\mathrm{s}, \mathrm{j}, \mathrm{k}, \mathrm{d}}$ & $\begin{array}{l}\text { delivery quantity of product } k \text { from distributor } s \text { to customer } j \\
\text { using mode of transport } d\end{array}$ \\
\hline $\mathrm{Ya}_{\mathrm{s}, \mathrm{j}, \mathrm{d}}$ & $\begin{array}{l}\text { if delivery is from distributor } s \text { to customer } j \text { using mode of } \\
\text { transport } d \text { then } \mathrm{Ya}_{\mathrm{s}, \mathrm{j}, \mathrm{d}}=1 \text {, otherwise } \mathrm{Ya}_{\mathrm{s}, \mathrm{j}, \mathrm{d}}=0\end{array}$ \\
\hline $\mathrm{Yb}_{\mathrm{s}, \mathrm{j}, \mathrm{d}}$ & $\begin{array}{l}\text { the number of courses from distributor } s \text { to customer } j \text { using } \\
\text { mode of transport } d\end{array}$ \\
\hline $\mathrm{Tc}_{\mathrm{s}}$ & $\begin{array}{l}\text { if distributor } s \text { participates in deliveries, then } \mathrm{Tc}_{\mathrm{s}}=1 \text {, } \\
\text { otherwise } \mathrm{Tc}_{\mathrm{s}}=0\end{array}$ \\
\hline $\mathrm{CW}$ & Arbitrarily large constant \\
\hline
\end{tabular}

\section{A. Objective function}

The objective function (1) defines the aggregate costs of the entire chain and consists of five elements. The first element comprises the fixed costs associated with the operation of the distributor involved in the delivery (e.g. distribution centre, warehouse, etc.). The second element corresponds to environmental costs of using various means of transport. Those costs are dependent on the number of courses of the given means of transport, and on the other hand, on the environmental levy, which in turn may depend on the use of fossil fuels and carbon-dioxide emissions [26],[27].

The third component determines the cost of the delivery from the manufacturer to the distributor. Another component is responsible for the costs of the delivery from the distributor to the end user (the store, the individual client, etc.). The last component of the objective function determines the cost of manufacturing the product by the given manufacturer.

Formulating the objective function in this manner allows comprehensive cost optimization of various aspects of supply chain management. Each subset of the objective function with the same constrains provides a subset of the optimization area and makes it much easier to search for a solution.

$$
\begin{gathered}
\sum_{s=1}^{E} F_{s} \cdot \mathrm{Tc}_{\mathrm{s}}+\sum_{\mathrm{d}=1}^{\mathrm{L}} \mathrm{Od}_{\mathrm{d}}\left(\sum_{\mathrm{i}=1}^{\mathrm{N}} \sum_{\mathrm{s}=1}^{\mathrm{E}} \mathrm{Xb}_{\mathrm{i}, \mathrm{s}, \mathrm{d}}+\sum_{\mathrm{s}=1}^{\mathrm{E}} \sum_{\mathrm{j}=1}^{\mathrm{M}} \mathrm{Yb}_{\mathrm{j}, \mathrm{s}, \mathrm{d}}\right)+ \\
\sum_{\mathrm{i}=1}^{\mathrm{N}} \sum_{\mathrm{s}=1}^{\mathrm{E}} \sum_{\mathrm{d}=1}^{\mathrm{L}} \mathrm{Koa}_{\mathrm{i}, \mathrm{d}, \mathrm{d}}+\sum_{\mathrm{s}=1}^{\mathrm{E}} \sum_{\mathrm{j}=1}^{\mathrm{M}} \sum_{\mathrm{d}=1}^{\mathrm{L}} \operatorname{Kog}_{\mathrm{s}, \mathrm{d}, \mathrm{d}}+\sum_{\mathrm{i}=1}^{\mathrm{N}} \sum_{\mathrm{k}=1}^{\mathrm{O}}\left(\mathrm{C}_{\mathrm{ik}} \cdot \sum_{\mathrm{s}=1}^{\mathrm{E}} \sum_{\mathrm{d}=1}^{\mathrm{L}} \mathrm{X}_{\mathrm{i}, \mathrm{s}, \mathrm{k}, \mathrm{d}}\right)
\end{gathered}
$$

\section{B. Constraints}

The model was based on constraints (2) .. (26) Constraint (2) specifies that all deliveries of product $k$ produced by the manufacturer $i$ and delivered to all distributors $s$ using mode of transport $d$ do not exceed the manufacturer's production capacity.

Constraint (3) covers all customer $j$ demands for product $k$ $\left(Z_{j, k}\right)$ through the implementation of delivery by distributors $s$ (the values of decision variables $Y_{i, s, k, d}$ ). The flow balance of each distributor $s$ corresponds to constraint (4). The possibility of delivery is dependent on the distributor's technical capabilities - constraint (5). Time constraint (6) ensures the terms of delivery are met. Constraints (7a), (7b), (8) guarantee deliveries with available transport taken into account. Constraints (9), (10), (11) set values of decision variables based on binary variables $T c_{s}, X a_{i, s, d}, \quad Y a_{s, j, d}$. Dependencies (12) and (13) represent the relationship based on which total costs are calculated. In general, these may be any linear functions. The remaining constraints (14)..(23) arise from the nature of the model (MILP).

Constraint (24) allows the distribution of exclusively one of the two selected products in the distribution center $s$. Similarly, constraint (25) allows the production of exclusively one of the two selected products in the factory $i$.

Constraint (26) allows the transport of exclusively one of the two selected products in the same route and transport unit. 
Those constraints result from technological, marketing, sales or safety reasons. Therefore, some products cannot be distributed and/or produced and/or transported together. The constraint can be re-used for different pairs of product $k$ and for some of or all distribution centers $s$ and factories $i$. A logical constraint like this cannot be easily implemented in a mathematical programming model. Only declarative application environments based on constraint satisfaction problem (CSP) make it possible to easy implement constraints such as (24), (25), (26).

The addition of constraints of that type changes the model class. It is a hybrid model (1)..(26).

$$
\begin{aligned}
& \sum_{s=1}^{E} \sum_{d=1}^{L} X_{i, s, k, d} \cdot R_{s, k} \leq W_{i, k} \text { for } \mathrm{i}=1 . . N, k=1 . . O \\
& \sum_{s=1}^{E} \sum_{d=1}^{L}\left(Y_{s, j, k, d} \cdot R_{s, k}\right) \geq Z_{j, k} \text { for } j=1 . . M, k=1 . . O \\
& \sum_{\mathrm{i}=1}^{N} \sum_{\mathrm{d}=1}^{\mathrm{L}} \mathrm{X}_{\mathrm{i}, \mathrm{s}, \mathrm{k}, \mathrm{d}}=\sum_{\mathrm{j}=1}^{\mathrm{M}} \sum_{\mathrm{d}=1}^{\mathrm{L}} \mathrm{Y}_{\mathrm{s}, \mathrm{k}, \mathrm{k}, \mathrm{d}} \text { for } \mathrm{s}=1 . . \mathrm{E}, \mathrm{k}=1 . . \mathrm{O} \\
& \sum_{\mathrm{k}=1}^{\mathrm{o}}\left(\mathrm{P}_{\mathrm{k}} \cdot \sum_{\mathrm{i}=1}^{\mathrm{N}} \sum_{\mathrm{d}=1}^{\mathrm{L}} \mathrm{X}_{\mathrm{i}, \mathrm{s}, \mathrm{k}, \mathrm{d}}\right) \leq \mathrm{Tc}_{\mathrm{s}} \cdot \mathrm{V}_{\mathrm{s}} \text { for } \mathrm{s}=1 . . \mathrm{E} \\
& \mathrm{Xa}_{\mathrm{i}, \mathrm{s}, \mathrm{d}} \cdot \mathrm{Tf}_{\mathrm{i}, \mathrm{s}, \mathrm{d}}+\mathrm{Xa}_{\mathrm{i}, \mathrm{s}, \mathrm{d}} \cdot \mathrm{Tp}_{\mathrm{s}, \mathrm{k}}+\mathrm{Ya}_{\mathrm{s}, \mathrm{j}, \mathrm{d}} \cdot \mathrm{Tm}_{\mathrm{s}, \mathrm{j}, \mathrm{s}} \leq \mathrm{Tc}_{\mathrm{j}, \mathrm{k}} \\
& \text { for } \mathrm{i}=1 . . \mathrm{N}, \mathrm{s}=1 . . \mathrm{E}, \mathrm{j}=1 . . \mathrm{M}, \mathrm{k}=1 . . \mathrm{O}, \mathrm{d}=1 . . \mathrm{L} \\
& \mathrm{R}_{\mathrm{i}, \mathrm{s,d}} \cdot \mathrm{Xb}_{\mathrm{i}, \mathrm{s}, \mathrm{d}} \cdot \mathrm{Pt}_{\mathrm{d}} \geq \mathrm{X}_{\mathrm{i}, \mathrm{s}, \mathrm{k}, \mathrm{d}} \cdot \mathrm{P}_{\mathrm{k}} \\
& \text { for } \mathrm{i}=1 . . \mathrm{N}, \mathrm{s}=1 . . \mathrm{E}, \mathrm{k}=1 . . \mathrm{O}, \mathrm{d}=1 . . \mathrm{L} \\
& \mathrm{R} 2_{\mathrm{s}, \mathrm{j}, \mathrm{d}} \cdot \mathrm{Yb}_{\mathrm{s}, \mathrm{d}, \mathrm{d}} \cdot \mathrm{Pt}_{\mathrm{d}} \geq \mathrm{Y}_{\mathrm{s}, \mathrm{j}, \mathrm{k}, \mathrm{d}} \cdot \mathrm{P}_{\mathrm{k}} \\
& \text { for } s=1 . . E, j=1 . . M, k=1 . . O, d=1 . . L \\
& \sum_{\mathrm{i}=1}^{\mathrm{N}} \sum_{\mathrm{s}=1}^{\mathrm{E}} \mathrm{Xb}_{\mathrm{i}, \mathrm{s}, \mathrm{d}}+\sum_{\mathrm{j}=1}^{\mathrm{M}} \sum_{\mathrm{s}=1}^{\mathrm{E}} \mathrm{Yb}_{\mathrm{j}, \mathrm{s}, \mathrm{d}} \leq \mathrm{Zt}_{\mathrm{d}} \text { for } \mathrm{d}=1 . . \mathrm{L} \\
& \sum_{\mathrm{i}=1}^{\mathrm{N}} \sum_{\mathrm{d}=1}^{\mathrm{L}} \mathrm{Xb}_{\mathrm{i}, \mathrm{s}, \mathrm{d}} \leq \mathrm{CW} \cdot \mathrm{Tc}_{\mathrm{s}} \text { for } \mathrm{s}=1 . . \mathrm{E} \\
& \mathrm{Xb}_{\mathrm{i}, \mathrm{s}, \mathrm{d}} \leq \mathrm{CW} \cdot \mathrm{Xa}_{\mathrm{i}, \mathrm{s}, \mathrm{d}} \text { for } \mathrm{i}=1 . . \mathrm{N}, \mathrm{s}=1 . . \mathrm{E}, \mathrm{d}=1 . . \mathrm{L} \\
& \mathrm{Yb}_{s, \mathrm{j}, \mathrm{d}} \leq \mathrm{CW} \cdot \mathrm{Ya}_{\mathrm{s}, \mathrm{j}, \mathrm{d}} \text { for } \mathrm{s}=1 . . \mathrm{E}, \mathrm{j}=1 . . \mathrm{M}, \mathrm{d}=1 . . \mathrm{L} \\
& \mathrm{Koa}_{\mathrm{i}, \mathrm{s}, \mathrm{d}}=\mathrm{A}_{\mathrm{i}, \mathrm{s}, \mathrm{d}} \cdot \mathrm{Xb}_{\mathrm{i}, \mathrm{s}, \mathrm{d}}+\sum_{\mathrm{k}=1}^{\mathrm{o}} \mathrm{K} 1_{\mathrm{i}, \mathrm{s}, \mathrm{k}, \mathrm{d}} \cdot \mathrm{X}_{\mathrm{i}, \mathrm{s}, \mathrm{k}, \mathrm{d}} \\
& \text { for } \mathrm{i}=1 . . \mathrm{N}, \mathrm{s}=1 . . \mathrm{E}, \mathrm{d}=1 \text {.. } \mathrm{L} \\
& \mathrm{Kog}_{\mathrm{s}, \mathrm{j}, \mathrm{d}}=\mathrm{G}_{\mathrm{s}, \mathrm{j}, \mathrm{d}} \cdot \mathrm{Yb}_{\mathrm{j}, \mathrm{s}, \mathrm{d}}+\sum_{\mathrm{k}=1}^{\mathrm{o}} \mathrm{K} 2_{\mathrm{s}, \mathrm{j}, \mathrm{d}, \mathrm{d}} \cdot \mathrm{Y}_{\mathrm{s}, \mathrm{j}, \mathrm{k}, \mathrm{d}} \\
& \text { for } \mathrm{s}=1 . . \mathrm{E}, \mathrm{j}=1 . . \mathrm{M}, \mathrm{d}=1 . . \mathrm{L} \\
& \mathrm{X}_{\mathrm{i}, \mathrm{s}, \mathrm{k}, \mathrm{d}} \geq 0 \text { for } \mathrm{i}=1 . . \mathrm{N}, \mathrm{s}=1 . . \mathrm{E}, \mathrm{k}=1 . .0, \mathrm{~d}=1 . . \mathrm{L} \\
& \mathrm{Xb}_{\mathrm{is.s}} \geq 0 \text { for } \mathrm{i}=1 . . \mathrm{N}, \mathrm{s}=1 . . \mathrm{E}, \mathrm{d}=1 . . \mathrm{L} \text {, } \\
& \mathrm{Yb}_{\mathrm{s}, \mathrm{j}, \mathrm{d}} \geq 0 \text { for } \mathrm{s}=1 . . \mathrm{E}, \mathrm{j}=2 . . \mathrm{M}, \mathrm{d}=1 . . \mathrm{L} \text {, } \\
& \mathrm{X}_{\mathrm{i}, \mathrm{s}, \mathrm{k}, \mathrm{d}} \in \mathrm{C} \text { for } \mathrm{i}=1 . . \mathrm{N}, \mathrm{s}=1 . . \mathrm{E}, \mathrm{k}=1 . .0, \mathrm{~d}=1 . . \mathrm{L} \text {, } \\
& \mathrm{Xb}_{\mathrm{i}, \mathrm{s} \mathrm{d}} \in \mathrm{C} \text { for } \mathrm{i}=1 . . \mathrm{N}, \mathrm{s}=1 . . \mathrm{E}, \mathrm{d}=1 . . \mathrm{L} \\
& \mathrm{Y}_{\mathrm{s}, \mathrm{j}, \mathrm{k}, \mathrm{d}} \in \mathrm{C} \text { for } \mathrm{s}=1 . . \mathrm{E}, \mathrm{j}=1 . . \mathrm{M}, \mathrm{k}=1 . .0, \mathrm{~d}=1 . . \mathrm{L} \\
& \mathrm{Yb}_{\mathrm{s}, \mathrm{j}, \mathrm{d}} \in \mathrm{C} \text { for } \mathrm{s}=1 . . \mathrm{E}, \mathrm{j}=1 . . \mathrm{M}, \mathrm{d}=1 . . \mathrm{L} \text {, } \\
& \mathrm{Xa}_{\mathrm{i}, \mathrm{s}, \mathrm{d}} \in\{0,1\} \text { for } \mathrm{i}=1 . . \mathrm{N}, \mathrm{s}=1 . . \mathrm{E}, \mathrm{d}=1 . . \mathrm{L} \text {, } \\
& \mathrm{Ya}_{\mathrm{s}, \mathrm{j}, \mathrm{d}} \in\{0,1\} \text { for } \mathrm{s}=1 . . \mathrm{E}, \mathrm{j}=2 . . \mathrm{M}, \mathrm{d}=1 . . \mathrm{L} \text {, } \\
& \mathrm{Tc}_{\mathrm{s}} \in\{0,1\} \text { for } \mathrm{s}=1 . . \mathrm{E}
\end{aligned}
$$

\section{Model transformation}

Due to the nature of the decision problem (adding up decision variables and constraints involving a lot of variables), the constraint propagation efficiency decreases dramatically. Constraint propagation is one of the most important methods in CLP affecting the efficiency and effectiveness of the CLP and novel hybrid implementation platform (Fig. 1). For that reason, research into more efficient and more effective methods of constraint propagation was conducted. The results included different representation of the problem and the manner of its implementation. The classical problem modeling in the CLP environment consists in building a set of predicates with parameters. Each CLP predicate has a corresponding multi-dimensional vector representation. While modeling both problems, (1) .. (23) and (1) .. (26), quantities $i, s, k, d$ and decision variable $X_{i, s, k, d}$ were vector parameters. The process of finding the solution may consist in using the constraints propagation methods, labeling of variables and the backtracking mechanism [13]. The quality of constraints propagation and the number of backtrackings are affected to a high extent by the number of parameters that must be specified/labeled in the given predicate/vector. In both models presented above, the classical problem representation included five parameters: $i, s, k, d$ and $X_{i, s, k, d}$. Considering the domain size of each parameter, the process is complex and time-consuming. Our idea was to transform the problem by changing its representation without changing the very problem. All permissible routes were first generated based on the fixed data and a set of orders, then the specific values of parameters $i, s, k, d$ were assigned to each of the routes. In this way, only decision variables $X_{i, s, k, d}$ (deliveries) had to be specified. This transformation allows only one parameter search instead of five. This is possible due to the flexibility and features of the CLP environment.

This transformation fundamentally improved the efficiency of the constraint propagation and reduced the number of backtracks. A route model is a name adopted for the models that underwent the transformation (MILP-R).

\section{Decision-making support}

The proposed models in this platform can support decision-making in the following areas:

- the optimization of total cost of the supply chain (Table II);

- the selection of the transport fleet number, capacity and modes for specific total costs;

- the sizing of distributor warehouses and the study of their impact on the overall costs (Table III, Fig. 3.);

- the selection of transport routes for optimal total cost (Fig. 4.).

Detailed studies of these topics are being conducted and will be described in our future articles. 


\section{NUMERICAL EXPERIMENTS}

In order to verify and evaluate the proposed approach, many numerical experiments were performed. All the examples relate to the supply chain with seven manufacturers $(i=1 . .7)$, three distributors $(s=1 . .3)$, ten customers $(j=1 . .10)$, three modes of transport $(d=1 . .3)$, and twenty types of products $(k=1 . .20)$. Experiments began with nine examples of P1 .. P9 for the optimization MILP model (1) .. (23). The examples differ in terms of capacity available to the distributors $s$ $\left(V_{s}\right)$, the number of transport units using the mode of transport $d\left(Z t_{d}\right)$ and the number of orders $(\mathrm{No})$. The first series of experiments was designed to show the benefits and advantages of the hybrid approach. For this purpose the model (1) .. (23) was implemented in both the hybrid and integer programming environments. The experiments that follow were conducted to optimize examples P1..P9 for the optimization HP model (1) .. (26) in the hybrid approach.

Numeric data of input parameters for examples P1.. P9 are shown in Appendix A1. The results in the form of the objective function and the computation time are shown in Table II.

TABLE II

THE RESULTS OF NUMERICAL EXAMPLES FOR BOTH APPROACHES

\begin{tabular}{|c|c|c|c|c|c|c|}
\hline \multirow{3}{*}{$\mathbf{P}(\mathbf{N o})$} & \multirow{2}{*}{\multicolumn{2}{|c|}{$\begin{array}{c}\text { Hybrid Approach } \\
\text { MILP-R } \\
\end{array}$}} & \multirow{2}{*}{\multicolumn{2}{|c|}{$\begin{array}{c}\begin{array}{c}\text { Integer } \\
\text { Programming }\end{array} \\
\text { MILP }\end{array}$}} & \multicolumn{2}{|c|}{ Hybrid Approach } \\
\hline & & & & & \multicolumn{2}{|c|}{ HM } \\
\hline & $F c$ & $T$ & Fc & $T$ & $F \boldsymbol{F c}$ & $T$ \\
\hline P1(100) & 10791 & 416 & 15459 & $900^{* *}$ & 10891 & 402 \\
\hline $\mathrm{P} 2(90)$ & 9263 & 323 & 9636 & $900^{* *}$ & 9377 & 452 \\
\hline $\mathrm{P} 3(80)$ & 8388 & 522 & 8854 & $900^{* * *}$ & 8522 & 438 \\
\hline $\mathrm{P} 4(60)$ & 6330 & 345 & 6330 & $900^{* *}$ & 6444 & 383 \\
\hline $\mathrm{P5}(40)$ & 4473 & 203 & 4473 & 743 & 4708 & 223 \\
\hline $\mathrm{P} 6(30)$ & 3488 & 83 & 3488 & 503 & 3664 & 181 \\
\hline P7(20) & 2877 & 23 & 2877 & 383 & 2894 & 31 \\
\hline P8(15) & 2266 & 7 & 2266 & 503 & 2282 & 13 \\
\hline $\mathrm{P} 9(10)$ & 1756 & 2 & 1756 & 355 & 1756 & 2 \\
\hline Fc & \multicolumn{6}{|c|}{ the value of the objective function } \\
\hline $\mathbf{T}$ & \multicolumn{6}{|c|}{ time of finding solution (in seconds) } \\
\hline * & \multicolumn{6}{|c|}{ the feasible value of the objective function after the time $\mathrm{T}$} \\
\hline$* *$ & \multicolumn{6}{|c|}{ calculation was stopped after $900 \mathrm{~s}$} \\
\hline MILP & \multicolumn{6}{|c|}{ MILP model implementation in the IP environment. } \\
\hline MILPT & \multicolumn{6}{|c|}{$\begin{array}{l}\text { MILP model after transformation-implementation in the } \\
\text { hybrid implementation platform. }\end{array}$} \\
\hline HM & \multicolumn{6}{|c|}{$\begin{array}{l}\text { Hybrid model after transformation-implementation in the } \\
\text { hybrid implementation platform. }\end{array}$} \\
\hline
\end{tabular}

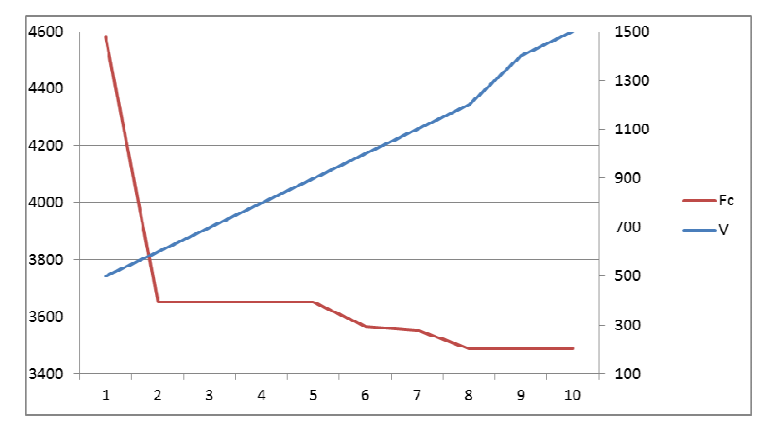

Fig. 3 The value of the objective function depending on the parameter $\mathrm{V}$ (Example P6)

For each example the solution for the MILP-R implementation was found faster than that for the MILP implementation. Moreover, for examples P1 .. P4, the traditional approach based on integer programming gives only feasible solution (calculation was stopped after $900 \mathrm{~s}$ ) despite using highly efficient MILP solvers. It is obvious that the solution of the hybrid model (HM) was, due to its nature, only possible using the hybrid platform. Also, the proposed environment brought the expected results. The results were obtained in only a slightly longer period of time than that necessary for MILP-R (examples P1 .. P9).

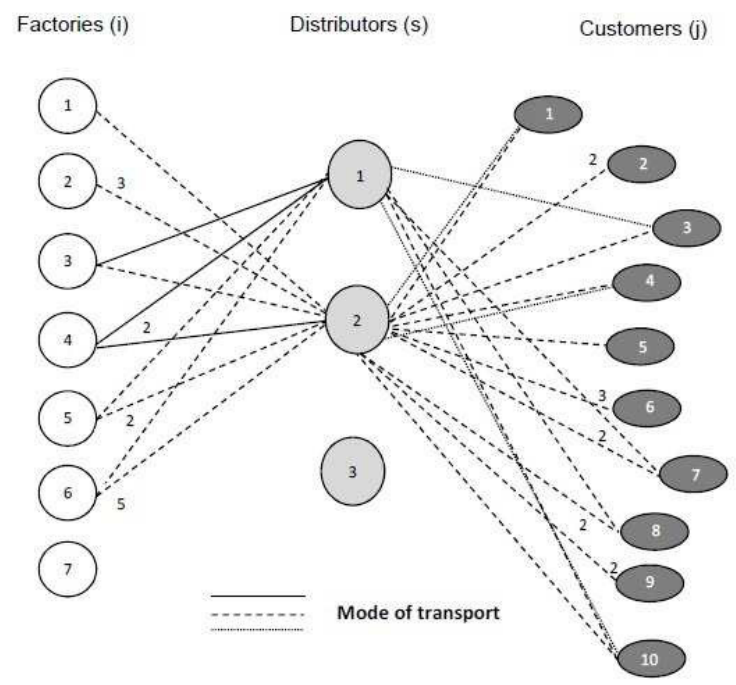

Fig. 4 Optimal transport network for the optimal solution $\left(\mathrm{Fc}^{\mathrm{opt}}=8388\right)$ for P3 (no number means one)

TABLE III

ANALYSIS OF THE IMPACT PARAMETER V $\mathrm{V}_{\mathrm{S}}$ FOR FC (EXAMPLE P6)

\begin{tabular}{|c|c|c|c|c|}
\hline \multirow{2}{*}{$\mathbf{V}=\mathbf{V}_{\mathbf{1}}=\mathbf{V}_{\mathbf{2}}=\mathbf{V}_{\mathbf{3}}$} & \multirow{2}{*}{$\mathbf{F}^{\mathbf{p p t}}$} & \multicolumn{3}{|c|}{ Distributor capacity (Vs) utilization } \\
\cline { 3 - 5 } & & $\mathbf{V}_{\mathbf{1}}$ & $\mathbf{V}_{\mathbf{2}}$ & $\mathbf{V}_{\mathbf{3}}$ \\
\hline 500 & 4581 & 470 & 336 & 350 \\
\hline 600 & 3653 & 570 & 586 & 0 \\
\hline 700 & 3653 & 570 & 586 & 0 \\
\hline 800 & 3653 & 570 & 586 & 0 \\
\hline 900 & 3653 & 256 & 900 & 0 \\
\hline 1000 & 3567 & 188 & 968 & 0 \\
\hline 1100 & 3554 & 130 & 1026 & 0 \\
\hline 1200 & 3488 & 0 & 1156 & 0 \\
\hline 1400 & 3488 & 0 & 1156 & 0 \\
\hline
\end{tabular}

\section{CONCLUSION}

The efficiency of the proposed approach is based on the reduction of the combinatorial problem. This means that using the hybrid approach practically for all models of this class, the same or better solutions are found faster (the optimal instead of the feasible solutions). Another element contributing to the high efficiency of the method is a possibility to determine the values or ranges of values for some of the decision variables (phase P3). All effective LINGO solvers can be used in the hybrid method.

It should be emphasized that with the used approach it is possible not only to solve optimization problems faster, but also to solve much larger problems than in the [17].

Therefore, the proposed solution is highly recommended for all types of decision problems in supply chain or for other problems with similar structure. This structure is characterized by the constraints of many discrete decision 
variables and their summation. Furthermore, this method can model and solve problems with logical constraints.

In addition to the undoubted effectiveness of the proposed hybrid approach, should underline the possibility of modeling decision problems. The proposed approach can be created a new class of decision problems - hybrid problems that are not only familiar with the constraints from mathematical programming models but also new types of constraints such as logical constraints.

Further work will focus on running the optimization models with non-linear and other logical constraints, multiobjective, uncertainty etc. in the hybrid optimization framework. It is planned also apply this method to various types of scheduling problems [14],[28],[29].

\section{APPENDIX A1}

TABLE IV

DATA FOR COMPUTATIONAL EXAMPLES P1,P2,P3,P4,P5,P6,P7,P8,P9

\begin{tabular}{|c|l|l|l|}
\hline $\mathbf{k}$ & $\mathbf{V}_{\mathbf{k}}$ & $\mathbf{k}$ & $\mathbf{V}_{\mathbf{k}}$ \\
\hline 01 & 1 & 11 & 8 \\
\hline 02 & 2 & 12 & 4 \\
\hline 03 & 5 & 13 & 5 \\
\hline 04 & 9 & 14 & 5 \\
\hline 05 & 3 & 15 & 7 \\
\hline 06 & 4 & 16 & 8 \\
\hline 07 & 5 & 17 & 9 \\
\hline 08 & 6 & 18 & 1 \\
\hline 09 & 7 & 19 & 4 \\
\hline 10 & 8 & 20 & 6 \\
\hline
\end{tabular} \mid \begin{tabular}{|c|}
\hline 01 \\
\hline 02 \\
\hline 03 \\
\hline 04 \\
\hline 06 \\
\hline 07 \\
\hline 08 \\
\hline 09 \\
\hline 10 \\
\hline
\end{tabular}

\begin{tabular}{|c|c|c|}
\hline $\mathbf{s}$ & $\mathbf{V}_{\mathbf{s}}$ & $\mathbf{F}_{\mathbf{s}}$ \\
\hline $\mathrm{C} 1$ & 4000 & 100 \\
\hline $\mathrm{C} 2$ & 4000 & 100 \\
\hline $\mathrm{C} 3$ & 4000 & 400 \\
\hline
\end{tabular}

\begin{tabular}{|c|c|c|c|}
\hline $\mathbf{d}$ & $\mathbf{P t}_{\mathbf{s}}$ & $\mathbf{Z t}_{\mathbf{s}}$ & $\mathbf{O d}_{\mathbf{s}}$ \\
\hline S1 & 400 & 25 & 240 \\
\hline S2 & 200 & 40 & 180 \\
\hline S3 & 100 & 80 & 100 \\
\hline
\end{tabular}

\begin{tabular}{|c|}
\hline $\mathbf{i}$ \\
\hline 01 \\
\hline 02 \\
\hline 03 \\
\hline 04 \\
\hline 05 \\
\hline 06 \\
\hline 07 \\
\hline
\end{tabular}

\begin{tabular}{|c|c|}
\hline $\mathbf{k}$ & $\mathbf{k}$ \\
\hline 06 & 07 \\
\hline 09 & 10 \\
\hline
\end{tabular}

\begin{tabular}{|c|c|c|c|c|}
\hline $\mathbf{i}$ & $\mathbf{s}$ & $\mathbf{d}$ & $\mathbf{K}_{\mathbf{i}, \mathbf{d}, \mathbf{d}}$ & $\mathbf{T}_{\mathbf{i}, \mathbf{s , d}}$ \\
\hline 03 & 01 & 01 & 35 & 4 \\
\hline
\end{tabular} \begin{tabular}{|l|l|l|l|l|}
\hline 03 & 01 & 01 & 35 & 4 \\
\hline 04 & 01 & 01 & 44 & 5 \\
\hline
\end{tabular} \begin{tabular}{|l|l|l|l|l|}
\hline 07 & 01 & 01 & 17 & 2 \\
\hline 01 & 01 & 02 & 5 & 1 \\
\hline
\end{tabular} \begin{tabular}{|l|l|l|c|c|}
\hline 01 & 01 & 02 & 5 & 1 \\
\hline 02 & 01 & 02 & 15 & 2 \\
\hline 03 & 01 & 02 & 18 & 3 \\
\hline
\end{tabular} \begin{tabular}{|l|l|l|l|l|}
\hline 03 & 01 & 02 & 18 & 3 \\
\hline 04 & 01 & 02 & 22 & 4 \\
\hline
\end{tabular} \begin{tabular}{|l|l|l|l|l|}
\hline 05 & 01 & 02 & 16 & 3 \\
\hline 06 & 01 & 02 & 18 & 3 \\
\hline 07 & 01 & 01 & 8 & 1 \\
\hline
\end{tabular} \begin{tabular}{|l|l|l|c|c|}
\hline 07 & 01 & 01 & 8 & 1 \\
\hline 03 & 02 & 01 & 46 & 5 \\
\hline 04 & 02 & 01 & 38 & 4 \\
\hline
\end{tabular} \begin{tabular}{|l|l|l|l|l|}
\hline 04 & 02 & 01 & 38 & 4 \\
\hline 07 & 02 & 01 & 35 & 4 \\
\hline 01 & 02 & 02 & 18 & 3 \\
\hline
\end{tabular} \begin{tabular}{|l|l|l|l|l|}
\hline 01 & 02 & 02 & 18 & 3 \\
\hline 02 & 02 & 02 & 14 & 2 \\
\hline
\end{tabular} \begin{tabular}{|l|l|l|l|l|}
\hline 03 & 02 & 02 & 24 & 4 \\
\hline 04 & 02 & 02 & 17 & 3 \\
\hline
\end{tabular}

\begin{tabular}{|c|c|c|c|c|}
\hline 04 & 02 & 02 & 17 & 3 \\
\hline 05 & 02 & 02 & 8 & 1 \\
\hline
\end{tabular}
\begin{tabular}{|l|l|l|l|l|}
\hline 06 & 02 & 02 & 5 & 1 \\
\hline 07 & 02 & 02 & 17 & 3 \\
\hline
\end{tabular} \begin{tabular}{|c|c|c|c|c|}
\hline 07 & 02 & 02 & 17 & 3 \\
\hline 03 & 03 & 01 & 5 & 1 \\
\hline
\end{tabular} \begin{tabular}{|c|c|c|c|c|}
\hline 03 & 03 & 01 & 5 & 1 \\
\hline 04 & 03 & 01 & 34 & 4 \\
\hline 07 & 03 & 01 & 48 & 5 \\
\hline
\end{tabular} \begin{tabular}{|l|l|l|l|l|}
\hline 07 & 03 & 01 & 48 & 5 \\
\hline 01 & 03 & 02 & 15 & 3 \\
\hline
\end{tabular} \begin{tabular}{|l|l|l|l|l|}
\hline 02 & 03 & 02 & 30 & 5 \\
\hline
\end{tabular}

\begin{tabular}{|c|c|c|c|c|}
\hline 03 & 03 & 02 & 5 & 1 \\
\hline 04 & 03 & 02 & 15 & 3 \\
\hline 05 & 03 & 02 & 15 & 3 \\
\hline
\end{tabular}

\begin{tabular}{|l|l|l|l|l|}
\hline 04 & 03 & 02 & 15 & 3 \\
\hline 05 & 03 & 02 & 15 & 3 \\
\hline
\end{tabular}

\begin{tabular}{|c|c|c|l|}
\hline $\mathbf{i}$ & $\mathbf{k}$ & $\mathbf{W}_{\mathbf{i}, \mathbf{k}}$ & $\mathbf{C}_{\mathbf{i}, \mathbf{k}}$ \\
\hline 01 & 01 & 500 & 0 \\
\hline 01 & 02 & 500 & 0 \\
\hline 01 & 03 & 500 & 50 \\
\hline 01 & 04 & 500 & 50 \\
\hline 02 & 01 & 500 & 50 \\
\hline 02 & 02 & 500 & 50 \\
\hline 02 & 03 & 500 & 0 \\
\hline 02 & 04 & 500 & 0 \\
\hline 03 & 05 & 500 & 0 \\
\hline 03 & 06 & 500 & 0 \\
\hline 03 & 07 & 500 & 0 \\
\hline 03 & 08 & 500 & 0 \\
\hline 04 & 08 & 500 & 30 \\
\hline 04 & 09 & 500 & 0 \\
\hline 04 & 10 & 500 & 0 \\
\hline 04 & 11 & 500 & 0 \\
\hline 07 & 05 & 500 & 40 \\
\hline 07 & 06 & 500 & 30 \\
\hline 07 & 07 & 500 & 40 \\
\hline 07 & 08 & 500 & 50 \\
\hline 07 & 09 & 500 & 40 \\
\hline 07 & 10 & 500 & 60 \\
\hline 07 & 11 & 500 & 10 \\
\hline 05 & 12 & 500 & 0 \\
\hline 05 & 13 & 500 & 0 \\
\hline 05 & 14 & 500 & 10 \\
\hline 05 & 18 & 500 & 0 \\
\hline 05 & 19 & 500 & 0 \\
\hline
\end{tabular}

\begin{tabular}{|l|l|l|l|l|}
\hline 06 & 03 & 02 & 20 & 4 \\
\hline 07 & 03 & 02 & 22 & 3 \\
\hline
\end{tabular}

\begin{tabular}{|c|c|c|c|}
\hline 05 & 20 & 500 & 20 \\
\hline 06 & 14 & 500 & 0 \\
\hline 06 & 15 & 500 & 0 \\
\hline 06 & 16 & 500 & 0 \\
\hline 06 & 17 & 500 & 0 \\
\hline 06 & 18 & 500 & 20 \\
\hline 06 & 19 & 500 & 20 \\
\hline 06 & 17 & 500 & 0 \\
\hline 06 & 20 & 500 & 0 \\
\hline
\end{tabular}

\begin{tabular}{|c|c|c|c|c|c|c|c|c|c|}
\hline $\mathbf{s}$ & $\mathbf{j}$ & $\mathbf{d}$ & $\mathbf{K}_{\mathbf{s , j ,}, \mathbf{d}}$ & $\mathbf{T}_{\mathbf{s , j}, \mathbf{d}}$ & $\mathbf{s}$ & $\mathbf{j}$ & $\mathbf{d}$ & $\mathbf{K}_{\mathbf{s , j}, \mathbf{d}}$ & $\mathbf{T}_{\mathbf{s , j}, \mathbf{d}}$ \\
\hline 01 & 01 & 02 & 10 & 1 & 02 & 05 & 02 & 16 & 2 \\
\hline 01 & 02 & 02 & 29 & 3 & 02 & 06 & 02 & 5 & 1 \\
\hline 01 & 03 & 02 & 34 & 3 & 02 & 07 & 02 & 35 & 4 \\
\hline 01 & 04 & 02 & 44 & 4 & 02 & 08 & 02 & 36 & 4 \\
\hline 01 & 05 & 02 & 31 & 3 & 02 & 09 & 02 & 28 & 3 \\
\hline 01 & 06 & 02 & 35 & 3 & 02 & 10 & 02 & 41 & 5 \\
\hline 01 & 07 & 02 & 17 & 2 & 02 & 01 & 03 & 26 & 3 \\
\hline 01 & 08 & 02 & 45 & 5 & 02 & 02 & 03 & 16 & 2 \\
\hline 01 & 09 & 02 & 57 & 6 & 02 & 03 & 03 & 36 & 3 \\
\hline 01 & 10 & 02 & 17 & 2 & 02 & 04 & 03 & 6 & 3 \\
\hline 01 & 01 & 03 & 5 & 1 & 02 & 05 & 03 & 5 & 2 \\
\hline 01 & 02 & 03 & 19 & 3 & 02 & 06 & 03 & 25 & 1 \\
\hline 01 & 03 & 03 & 24 & 3 & 02 & 07 & 03 & 26 & 3 \\
\hline 01 & 04 & 03 & 34 & 4 & 02 & 08 & 03 & 26 & 3 \\
\hline 01 & 05 & 03 & 21 & 3 & 02 & 09 & 03 & 18 & 2 \\
\hline 01 & 06 & 03 & 25 & 3 & 02 & 10 & 03 & 31 & 4 \\
\hline 01 & 07 & 03 & 7 & 2 & 03 & 01 & 02 & 33 & 4 \\
\hline 01 & 08 & 03 & 35 & 5 & 03 & 02 & 02 & 59 & 6 \\
\hline 01 & 09 & 03 & 40 & 6 & 03 & 03 & 02 & 5 & 1 \\
\hline 01 & 10 & 03 & 7 & 2 & 03 & 04 & 02 & 34 & 4 \\
\hline 02 & 01 & 02 & 36 & 4 & 03 & 05 & 02 & 30 & 4 \\
\hline 02 & 02 & 02 & 26 & 3 & 03 & 06 & 02 & 45 & 5 \\
\hline 02 & 03 & 02 & 46 & 4 & 03 & 07 & 02 & 48 & 5 \\
\hline 02 & 04 & 02 & 38 & 4 & 03 & 08 & 02 & 69 & 7 \\
\hline 03 & 05 & 03 & 20 & 3 & 03 & 09 & 02 & 10 & 2 \\
\hline 03 & 06 & 03 & 30 & 4 & 03 & 10 & 02 & 52 & 6 \\
\hline 03 & 07 & 03 & 32 & 4 & 03 & 01 & 03 & 23 & 3 \\
\hline 03 & 08 & 03 & 50 & 6 & 03 & 02 & 03 & 40 & 4 \\
\hline 03 & 09 & 03 & 8 & 1 & 03 & 03 & 03 & 5 & 1 \\
\hline 03 & 10 & 03 & 40 & 6 & 03 & 04 & 03 & 24 & 3 \\
\hline
\end{tabular}

\begin{tabular}{|c|c|c|c|c|c|c|c|c|c|}
\hline Name & $\mathbf{k}$ & $\mathbf{j}$ & $\mathbf{T}_{\mathbf{j}, \mathbf{k}}$ & $\mathbf{Z}_{\mathbf{j}, \mathbf{k}}$ & Name & $\mathbf{k}$ & $\mathbf{j}$ & $\mathbf{T}_{\mathbf{j}, \mathbf{k}}$ & $\mathbf{Z}_{\mathbf{j}, \mathbf{k}}$ \\
\hline $\mathrm{z} 0101$ & 01 & 01 & 25 & 8 & $\mathrm{z} 0105$ & 05 & 01 & 30 & 10 \\
\hline $\mathrm{z} 0116$ & 16 & 01 & 50 & 7 & $\mathrm{z} 0106$ & 06 & 01 & 20 & 10 \\
\hline $\mathrm{z} 0201$ & 01 & 02 & 10 & 10 & $\mathrm{z} 0219$ & 19 & 02 & 20 & 10 \\
\hline $\mathrm{z} 0202$ & 02 & 02 & 40 & 8 & $\mathrm{z} 0220$ & 20 & 02 & 10 & 10 \\
\hline $\mathrm{z} 0301$ & 01 & 03 & 20 & 10 & $\mathrm{z} 0302$ & 02 & 03 & 10 & 10 \\
\hline $\mathrm{z} 1019$ & 19 & 10 & 15 & 8 & $\mathrm{z} 0303$ & 03 & 03 & 10 & 8 \\
\hline
\end{tabular}




\begin{tabular}{|c|c|c|c|c|c|c|c|c|c|}
\hline $\mathrm{z} 1020$ & 20 & 10 & 35 & 8 & z0419 & 19 & 04 & 30 & 10 \\
\hline $\mathrm{z} 0901$ & 01 & 09 & 30 & 10 & $\mathrm{z} 0420$ & 20 & 04 & 25 & 10 \\
\hline $\mathrm{z} 0401$ & 01 & 04 & 40 & 10 & $\mathrm{z} 0501$ & 01 & 05 & 15 & 10 \\
\hline $\mathrm{z} 0505$ & 05 & 05 & 60 & 8 & $\mathrm{z} 0502$ & 02 & 05 & 10 & 10 \\
\hline z1013 & 13 & 10 & 15 & 8 & z1015 & 15 & 10 & 10 & 8 \\
\hline z0911 & 11 & 09 & 20 & 10 & z1016 & 16 & 10 & 20 & 10 \\
\hline z0912 & 12 & 09 & 25 & 10 & z1017 & 17 & 10 & 20 & 10 \\
\hline z0806 & 06 & 08 & 50 & 8 & $\begin{array}{l}\text { z1018 } \\
\end{array}$ & 18 & 10 & 30 & 10 \\
\hline $\mathrm{z} 0807$ & 07 & 08 & 60 & 10 & z0917 & 17 & 09 & 30 & 10 \\
\hline $\mathrm{z} 0705$ & 05 & 07 & 60 & 10 & $\begin{array}{l}\text { Z0918 } \\
\end{array}$ & 18 & 09 & 30 & 10 \\
\hline z0706 & 06 & 07 & 20 & 8 & z0919 & 19 & 09 & 40 & 10 \\
\hline z0604 & 04 & 06 & 30 & 10 & $\mathrm{z} 0920$ & 20 & 09 & 40 & 8 \\
\hline $\mathrm{z} 0605$ & 05 & 06 & 35 & 10 & $\mathrm{z} 0809$ & 09 & 08 & 55 & 10 \\
\hline $\mathrm{z} 0606$ & 06 & 06 & 50 & 8 & $\mathrm{z} 0810$ & 10 & 08 & 30 & 8 \\
\hline $\mathrm{z} 0103$ & 03 & 01 & 10 & 8 & $\mathrm{z} 0811$ & 11 & 08 & 30 & 10 \\
\hline $\mathrm{z} 0209$ & 09 & 02 & 20 & 8 & z0812 & 12 & 08 & 20 & 10 \\
\hline $\begin{array}{l}\mathrm{z} 0309 \\
\end{array}$ & 09 & 03 & 30 & 10 & $\begin{array}{l}\mathrm{z} 0708 \\
\end{array}$ & 08 & 07 & 30 & 8 \\
\hline $\mathrm{z} 0410$ & 10 & 04 & 40 & 10 & $\mathrm{z} 0709$ & 09 & 07 & 60 & 10 \\
\hline $\mathrm{z} 0514$ & 14 & 05 & 30 & 8 & $\mathrm{z} 0710$ & 10 & 07 & 30 & 10 \\
\hline z0614 & 14 & 06 & 20 & 10 & $\mathrm{z} 0711$ & 11 & 07 & 10 & 10 \\
\hline $\mathrm{z} 0719$ & 19 & 07 & 10 & 8 & $\mathrm{z} 0609$ & 09 & 06 & 10 & 8 \\
\hline $\mathrm{z} 0720$ & 20 & 07 & 30 & 10 & $\mathrm{z} 0610$ & 10 & 06 & 30 & 10 \\
\hline z0818 & 18 & 08 & 25 & 8 & $\mathrm{z} 0611$ & 11 & 06 & 30 & 10 \\
\hline z0819 & 19 & 08 & 25 & 10 & z0612 & 12 & 06 & 30 & 10 \\
\hline $\mathrm{z} 0102$ & 02 & 01 & 15 & 10 & z0107 & 07 & 01 & 30 & 10 \\
\hline $\begin{array}{l}\mathrm{z} 0104 \\
\end{array}$ & 04 & 01 & 15 & 10 & 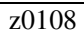 & 08 & 01 & 45 & 10 \\
\hline $\mathrm{z} 0203$ & 03 & 02 & 50 & 10 & z0109 & 09 & 01 & 30 & 10 \\
\hline $\mathrm{z} 0204$ & 04 & 02 & 20 & 10 & z0110 & 10 & 01 & 10 & 10 \\
\hline $\mathrm{z} 0304$ & 04 & 03 & 10 & 8 & $\mathrm{z} 0210$ & 10 & 02 & 20 & 10 \\
\hline $\mathrm{z} 0305$ & 05 & 03 & 30 & 10 & 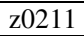 & 11 & 02 & 30 & 10 \\
\hline z0406 & 06 & 04 & 40 & 8 & z0217 & 17 & 02 & 20 & 10 \\
\hline z0407 & 07 & 04 & 50 & 10 & z0218 & 18 & 02 & 10 & 10 \\
\hline $\mathrm{z} 0512$ & 12 & 05 & 30 & 8 & z0308 & 08 & 03 & 30 & 10 \\
\hline $\mathrm{z} 0513$ & 13 & 05 & 20 & 10 & $\mathrm{z} 0312$ & 12 & 03 & 30 & 10 \\
\hline z0615 & 15 & 06 & 10 & 10 & z0315 & 15 & 03 & 20 & 10 \\
\hline
\end{tabular}

\section{References}

[1] Huang, G.Q., Lau, J.S.K., Mak, K.L., The impacts of sharing production information on supply chain dynamics: a review of the literature. International Journal of Production Research 41, 2003, pp.1483-1517.

[2] Kanyalkar, A.P., Adil, G.K., An integrated aggregate and detailed planning in a multi-site production environment using linear programming. International Journal of Production Research 43, 2005, pp. 4431-4454.

[3] Perea-lopez, E., Ydstie, B.E., Grossmann, I.E., A model predictive control strategy for supply chain optimization. Computers and Chemical Engineering 27, 2003, pp. 1201-1218.

[4] Park, Y.B.,. An integrated approach for production and distribution planning in supply chain management. International Journal of Production Research 43, 2005, pp. 1205-1224.

[5] Jung, H., Jeong, B., Lee, C.G., An order quantity negotiation model for distributor-driven supply chains. International Journal of Production Economics 111, 2008, pp. 147-158.

[6] Rizk, N., Martel, A., D'amours, S., Multi-item dynamic productiondistribution planning in process industries with divergent finishing stages. Computers and Operations Research 33, 2006, pp. 3600-3623.

[7] Selim, H., Am, C., Ozkarahan, I., Collaborative productiondistribution planning in supply chain: a fuzzy goal programming approach. Transportation Research Part E-Logistics and Transportation Review 44, 2008, pp. 396-419.

[8] Relich, M., Jakabova, M. A decision support tool for project portfolio management with imprecise data. In Proceedings of the 10th International Conference on Strategic Management and its Support by Information Systems, Valasske Mezirici 2013, Czech Republic, pp. 164-172.

[9] Chern, C.C., Hsieh, J.S., A heuristic algorithm for master planning that satisfies multiple objectives. Computers and Operations Research 34, 2007, pp. 3491-3513.
[10] Jang, Y.J., Jang, S.Y., Chang, B.M., Park, J., A combined model of network design and production/distribution planning for a supply network. Computers and Industrial Engineering 43, 2002, pp. 263-281.

[11] Timpe, C.H., Kallrath, J., Optimal planning in large multi-site production networks. European Journal of Operational Research 126, 2000, pp. 422-435.

[12] Mula J., Peidro D., Diaz-Madronero M., Vicens E., Mathematical programming models for supply chain production and transport planning, European Journal of Operational Research 204, 2010, pp. 377 390.

[13] Apt K., Wallace M., Constraint Logic Programming using Eclipse, Cambridge University Press, 2006.

[14] Sitek, P. A hybrid approach to the two-echelon capacitated vehicle routing problem ( $2 E-C V R P)$. In Recent Advances in Automation, Robotics and Measuring Techniques, Advances in Intelligent Systems and Computing 267, 2014; pp. 251-263.

[15] Bocewicz G., Banaszak Z. Declarative approach to cyclic steady states space refinement: periodic processes scheduling. In: International Journal of Advanced Manufacturing Technology, Vol. 67, Issue 1-4, 2013, 137-155.

[16] Rossi F., Van Beek P., Walsh T., Handbook of Constraint Programming (Foundations of Artificial Intelligence), Elsevier Science Inc. New York, NY, USA, 2006.

[17] Sitek P., Wikarek J., Cost optimization of supply chain with multimodal transport, Federated Conference on Computer Science and Information Systems (FedCSIS), 2012, pp. 1111-1118.

[18] Sitek P., Wikarek J., Supply chain optimization based on a MILP model from the perspective of a logistics provider, Management and Production Engineering Review, 2012, pp. 49-61.

[19] Relich, M. A declarative approach to new product development in the automotive industry. In Environmental Issues in Automotive Industry, Springer Berlin Heidelberg 2014, pp. 23-45.

[20] Jain V., Grossmann I.E., Algorithms for hybrid MILP/CP models for a class of optimization problems, INFORMS Journal on Computing 13(4), 2001, pp. 258-276.

[21] Milano M., Wallace M., Integrating Operations Research in Constraint Programming, Annals of Operations Research vol. 175 issue 1, 2010, pp. $37-76$.

[22] Achterberg T., Berthold T., Koch T., Wolter K., Constraint Integer Programming. A New Approach to Integrate CP and MIP, Lecture Notes in Computer Science Volume 5015, 2008, pp. 6-20.

[23] Bockmayr A., Kasper T., Branch-and-Infer, A Framework for Combining $C P$ and $I P$, Constraint and Integer Programming Operations Research/Computer Science Interfaces Series, Volume 27, 2004, pp. 59-87.

[24] Sitek, P., Wikarek, J., A hybrid approach to modeling and optimization for supply chain management with multimodal transport, IEEE Conference: 18th International Conference on Methods and Models in Automation and Robotics (MMAR), 2013, Pages: 777-782.

[25] Awasthi A., Grzybowska K., Chauhan S., S K Goyal., Investigating Organizational Characteristics for Sustainable Supply Chain Planning Under Fuzziness, Supply Chain Management Under Fuzziness, Studies in Fuzziness and Soft Computing 313, 2014,pp.81-100.

[26] Grzybowska K. Supply Chain Sustainability - analysing the enablers Springer Environmental issues in supply chain management - new trends and applications, P. Golinska, C. A.Romano (Eds.) 2012,pp. 2540.

[27] Grzybowska K., Kovács G. Developing Agile Supply Chains - system model, algorithms, applications Springer Agent and Multi-Agent Systems. Technologies and Applications, Lecture Notes in Computer Science, Jezic G. et. al. (eds.) 2012 pp. 576-585

[28] S.Deniziak, "Cost-efficient synthesis of multiprocessor heterogeneous systems", Control and Cybernetics, Vol.33, No.2, 2004, pp.341-355.

[29] Dang, Q.V., Nielsen, I. and Steger-Jensen, K., 2013, Scheduling a single mobile robot incorporated into production environment. In: P. Golinska, ed. EcoProduction \& Logistics - emerging trends and business practices, part 2, Springer-Verlag Berlin Heidelberg, ISBN 978-3-642-23552-8, ISBN 978-3-642-23553-5 (eBook), pp. 185-201. 